\title{
Molecular screening of the entA gene of Enterococcus faecium isolated from Food and clinical sources
}

\author{
Andalus Sabah Atiyah Marwa Hameed Alkhafaji \\ Department of Biology / College of Science / University of Baghdad \\ E-mail: andalussabah@gmail.com, drmarwahameed81@gmail.com
}

\begin{abstract}
Background: The microbial production of substances that have the potency to suppress the growth of other microorganisms is probably one of the prevalent defense strategy developed in nature, microorganisms produce a variable bunch of microbial defense systems, which include antibiotics, metabolic by-products, lytic agents, bacteriocins and others.

Objective: The purpose of the present study was to isolate and identify Enterococcus faecium isolates then detecting its ability of carrying the gene responsible for enterocin production in this species. Materials and methods: Out of 50 samples from different sources (food and clinical sources) were collected for the Enterococcus faecium isolation, and the isolated bacteria Enterococcus faecium (37) isolates were detected for their harboring of Enterocin A gene (entA), using conventional PCR technique.

Results: The identification revealed that $37(74 \%)$ isolates were considered as Enterococcus faecium, 20 isolates $(\mathbf{5 4 . 0 5} \%)$ out of food samples (10 samples were collected from dairies, 7 from vegetables and 3 from fish samples), and 17 isolates $45.9 \%$ out of clinical samples (11 from stool and 6 from urine source). Genotypic Detection done by the amplification of the enterocin coding gene (ent $A$ ), and the results revealed that all the isolates were harboring that gene despite of the phonotypical differences, that they amplified entA gene and the PCR product size (362 bp) was detected using agarose gel electrophoresis.

Conclusions: This study indicates the presence of Enterococcus spp. in food and clinical sources and the ability of these bacteria to produce antibacterial substances which is active against closely related clinical isolates.
\end{abstract}

Key words: Enterocin A, antibacterial, entA gene, Enterococcus.

\section{Introduction}

Enterococci are large genus of Gram-positive bacteria, catalase-negative, oxidase-negative, lactic acid producer (which is consider as a major end product of glucose fermentation), facultative anaerobic cocci generally looks like pairs or short chains (1). The genus Enterococcus which is belong to the family Enterococcaceae, one of the main families that belong to the order Lactobacillales and consider as one of the most important lactic acid bacteria, (entérocoque), that term was first coined and described by (2). Enterococci spp. are large genus of Gram-positive bacteria, non-spore-forming ovoid in shape, catalasenegative, oxidase-negative, bile salts tolerant and have the ability to hydrolyze esculin, generate lactic acid as its major end product of glucose fermentation, facultative anaerobic cocci which is usually appears in pairs or short chain, prevalent bacteria that have been isolated from different sources, could be in association with some plants, in the food products, or as a part of the gut microorganisms, as a commensal microorganisms in the gastrointestinal tract of human and animals (1)(3). Enterococci spp. are considered as LAB which are constitute of both commensal and opportunistic-pathogenic organisms and Due to their high durability towards many salts and acids, considered as highly appropriate to be a habitant in different food systems (4). Enterococcus species have been reported to produce bacteriocins which are ribosomally synthesized peptide or proteinaceous substances that inhibit the growth of food-borne and pathogenic bacteria, such as Listeria monocytogenes, Staphylococcus aureus (5). Enterococci spp . produces a broader 
range of bacteriocins which called enterocins, most of these enterocins have been isolated from E. faecalis and E. faecium, all were isolated from different sources such as dairy products, other food products including (fermented sausages, fish and vegetables), water, animals and human sources. The classification of bacteriocins was defined by (6). (Enterocin A) which is belongs to the class IIa bacteriocins, (isolated primarily from Enterococcus faecium) have an antimicrobial activity against important and pathogenic Listeria strains especially L. monocytogenes in fermented foods, and have a bioactivity over an extensive range of $\mathrm{pH}$ standards, temperature and $\mathrm{NaCl}$ levels, these possessions make it a possible applicant to be used as a food preservative and therapeutic antimicrobial agent (7).

\section{Materials and Methods \\ Isolation of bacteria}

Fifty samples (food and clinical sources) were collected randomly (from September to November 2019) the food samples were (row dairy products, leafy vegetables and fish) while the clinical samples were (urine and stool samples). All collected samples were inoculated on (Bile esculin-azide agar), incubated at $37^{\circ} \mathrm{C}$ for $24 \mathrm{hr}$. Enterococcus spp. have the ability to hydrolyze esculin in the presence of bile and convert the medium to a different color (8).

\section{Enterococcus Identification}

The collected samples in this study were isolated \& identified depending on the morphological structures and biochemical tests (9). VITEK2 was used to enhance and confirm the results of identification. The identification of Enterococcus was accomplished by the inoculation of samples on (Bile-esculin-azide Agar) at $37{ }^{\circ} \mathrm{C}$ / overnight, Enterococcus converted the media to black coffee brown color around the colonies (due to the hydrolysis of esculin). (ABC streaking method) was performed on (brain-heart infusion agar) in order to make pure colonies, and then overloaded VITEK kit by the samples. Enterococcus faecium species recovered (74\%) 37 samples), $54.05 \% 20$ isolates out of food samples (10 samples were collected from dairies, 7 from vegetables and 3 from fish samples), and 17 isolates) $45.9 \%$ out of clinical samples (11 from stool and 6 from urine source).

\section{Molecular Detection \\ DNA Extraction}

DNA was extracted using genomic DNA mini kit (Geneaid) protocol for Gram-positive bacteria were used as following:

Sample Preparation Step:

A volume of $1.5 \mathrm{ml}$ of bacterial broth was moved to a $1.5 \mathrm{ml}$ micro centrifuge tube and centrifuged for $1 \mathrm{~min}$ for16000 rpm then the supernatant was discarded.

Cell Wall Lysis Step:

A $200 \mu 1$ of Gram buffer (after ensuring the lysozyme was added and completely dissolved) was added to the sample in the $1.5 \mathrm{ml}$ micro-centrifuge tube then resuspend the pellet by pipette, and incubated at $37^{\circ} \mathrm{C}$ for about $30 \mathrm{~min}$. then a $20 \mu \mathrm{l}$ of Proteinase K (after ensuring the D DW was added) added to the sample in the $1.5 \mathrm{ml}$ micro-centrifuge tube then mixed well by vortex and incubated at $60{ }^{\circ} \mathrm{C}$ for at least $10 \mathrm{~min}$, after the incubation, $200 \mu 1$ of GB buffer was added to the sample and mixed by using vortex then was incubated at $70{ }^{\circ} \mathrm{C}$ for at least $10 \mathrm{~min}$ to guarantee the sample lysate is completely clear, throughout the incubation period the tubes were overturned every 3 minutes.

DNA binding Step:

$200 \mu$ l of absolute ethanol was supplemented and mixed well by shaking dynamically, at that point transported to the GD column and centrifuged at $14000 \mathrm{rpm}$ for $2 \mathrm{~min}$., after centrifugation the collection tube was discarded and the GD tube placed in a new one.

Washing Step: 
W1 buffer $(400 \mu \mathrm{l})$ was added then centrifuged at $14000 \mathrm{rpm}$ for $30 \mathrm{sec}$, and the flow through was ignored; $600 \mu 1$ of (washing buffer+ethanol) was added to the GD column and centrifuged at $14000 \mathrm{rpm}$ for $30 \mathrm{sec}$, after centrifugation the flow through was discarded, and the GD column was centrifuged for about 3 min at 14000rpm.

Elution Step:

An elution buffer $(50 \mu \mathrm{l})$ was added to the GD column after it was transferred to a clean microfuge tube and let stand for about 3 minutes then centrifuged at 14000-16000 rpm for 30 seconds.

\section{Agarose Gel Electrophoresis}

Agarose gel was prepared for the purity of DNA extraction detection, by liquefying $0.8 \mathrm{~g}$ of agarose in $100 \mathrm{ml}$ of $1 \mathrm{X}$ TBE buffer, boiled then cooled after few minutes, $5 \mu 1$ of ethidium bromide, agarose was poured out into the gel jar after it was cooled to prevent bubbles formation, and numerous wells were cautiously made with comb at one side of the gel about 5-10 mm away from the end of gel; after the ultimate solidification the comb was wisely detached and the container was put in the electrophoresis tank. Before loading to the gel wells with samples; DNA was first mixed with a loading dye, $5 \mu 1$ of every DNA sample were mixed with $2 \mu$ l loading dye, and then carefully transferred to the wells, and then after the closure of the electrophoresis tank with its lid an electric current was coordinated $(70 \mathrm{v} / 1 \mathrm{hr}$.).

\section{PCR Amplification of Enterocin A gene (entA)}

The primers used to detect Enterococcal enterocinA coding gene (entA) in this study as shown in Table (1).

Table (1): Primers and their sequences that used in this study for the amplification of entA gene

\begin{tabular}{|c|c|c|c|c|}
\hline Primer $($ entA $)$ & Sequences & Size & $\begin{array}{c}\text { Tm } \\
\left({ }^{\circ} \mathbf{C}\right)\end{array}$ & Reference \\
\hline $\begin{array}{c}\text { Forward } \\
(\text { entA })\end{array}$ & AAA ATA AAT GTA CGG TCG ATT GG & & 54.7 & $(4)$ \\
$\begin{array}{c}\text { Reverse } \\
(\text { ent } A)\end{array}$ & CCA GCA GTT CTT CCA ATT TCA & 362 & 55.7 & \\
\hline
\end{tabular}

The primer was provided as a lyophilized form, and then was ran in a sterilized distilled water to offer the ultimate concentration of $100 \mathrm{pmol} / \mu \mathrm{l}$ and stocked in the deep freezer till it used again in the PCR amplification. A conventional PCR was adapted to investigate the presence of this gene in the Enterococcal isolates.

DNA, Primers and PCR premix (Accupower, Bioneer) were liquefied by using a vortex and centrifuge to get the contents to the bottommost of tubes, PCR mixture was put up in a full volume of $25 \mu 1$ included $5 \mu 1$ of PCR premix, $2 \mu 1$ of each primer and $4 \mu 1$ of DNA template have been used, the remnant of volume was done with a sterilized deionized distilled water. Negative control was contained all materials except DNA template, and instead distilled water was added, after centrifugation of the PCR tubes (in order to get the contents to the bottom) all were placed in into thermo-cycler PCR instrument where the DNA was amplified, and the program of amplification was indicated in Table (2). 
Table (2): Thermal Cycler Program used to amplify the ent $A$ gene

\begin{tabular}{|c|c|c|}
\hline Name of cycle & Temperature & Time period \\
\hline Initial denaturation & $95^{\circ} \mathrm{C}$ & $5 \mathrm{~min}$ \\
Denaturation & $95^{\circ} \mathrm{C}$ & $30 \mathrm{sec}$ \\
Annealing & $51.5^{\circ} \mathrm{C}$ & $45 \mathrm{sec}$ \\
extension & $72^{\circ} \mathrm{C}$ & $45 \mathrm{sec}$ \\
Final extension & $72^{\circ} \mathrm{C}$ & $5 \mathrm{~min}$ \\
\hline
\end{tabular}

35 cycles

\section{Determination of PCR product}

After PCR amplification, gel electrophoresis was adopted to confirm the presence of amplification. gel was all set in $1.5 \%$ concentration for the determination of the PCR specificity and sensitivity by thawing $1.5 \mathrm{~g}$ of agarose powder in $100 \mathrm{ml}$ of $1 \mathrm{X}$ TBE buffer, and boiling, then the agarose was cooled out, then $5 \mu 1$ of Ethidium bromide was supplemented with mixing, agarose was added into the gel container after it was cooled to avoid bubbles development, and some wells were cautiously made with the comb at only one side of the gel about 5-10mm away from the end of gel; after ultimate solidification of the gel, the comb was carefully detached and the container was placed in the electrophoresis tank.

Five $\mu$ l of the 100 bp DNA ladder was loaded in the first well or in the middle of other wells of gel, then $5 \mu 1$ of every PCR product was loaded in the wells of gel, followed by the closure of the electrophoresis tank was with its distinctive cover and the electric current was coordinated (70v / 1.5-2 hr.).

\section{Results and Discussion}

Fifty samples (food and clinical isolates) were collected for Enterococcus faecium identification. Thirtyseven samples (74\%) were considered as E. faecium were specified relying on micro-scopical characteristics $\&$ biochemical tests as in Table (3).

Table(3) : Microscopical and biochemical tests of Enterococcus spp.

\begin{tabular}{|l|l|}
\hline Test & Result \\
\hline $40 \%$ Bile & Tolerant \\
\hline Esculin hydrolysis & Positive \\
\hline Azide tolerance & Positive \\
\hline Gram stain & Gram positive (cocci usually appears in pairs or short chain) \\
\hline Catalase & Negative \\
\hline Oxidase & Negative \\
\hline Glucose fermentation & Lactic acid producers \\
\hline
\end{tabular}


Enterococcus identification was achieved by direct inoculating of samples on Bile esculin-azide agar at $37^{\circ} \mathrm{C}$ for $24 \mathrm{hr}$., the positive result will transform the media to a dark brown color all over the place. (ABC streaking method) was accomplished to make pure colonies as shown in Figure (1).

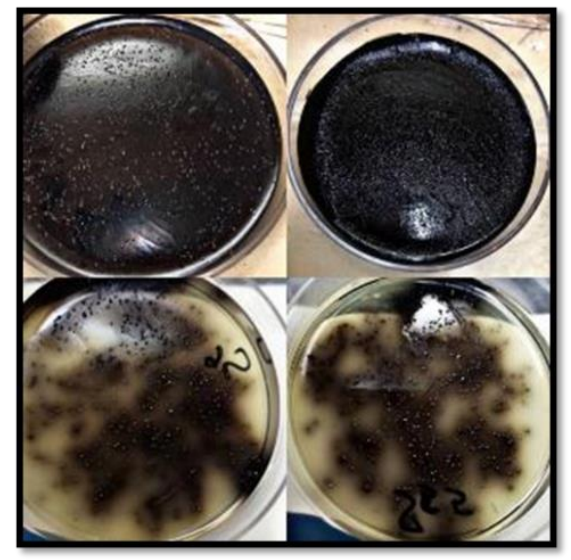

Figure (1): Enterococcus spp. colonies on Bile-Esculin azide agar, the media was altered to dark brown color around the colonies or the whole media appears as black coffee brown color because of the hydrolysis of esculin by Enterococcus

Then VITEK system was depended for further species identification and all the 37 isolated Enterococcal species were Enterococcus faecium. Enterococcus faecium species recovered (74\%) 37 samples, $54.05 \% 20$ isolates out of food samples (10 samples were collected from dairies, 7 from vegetables and 3 from fish samples), and 17 isolates $45.9 \%$ out of clinical samples (11 from stool and 6 from urine source) Figure (2).

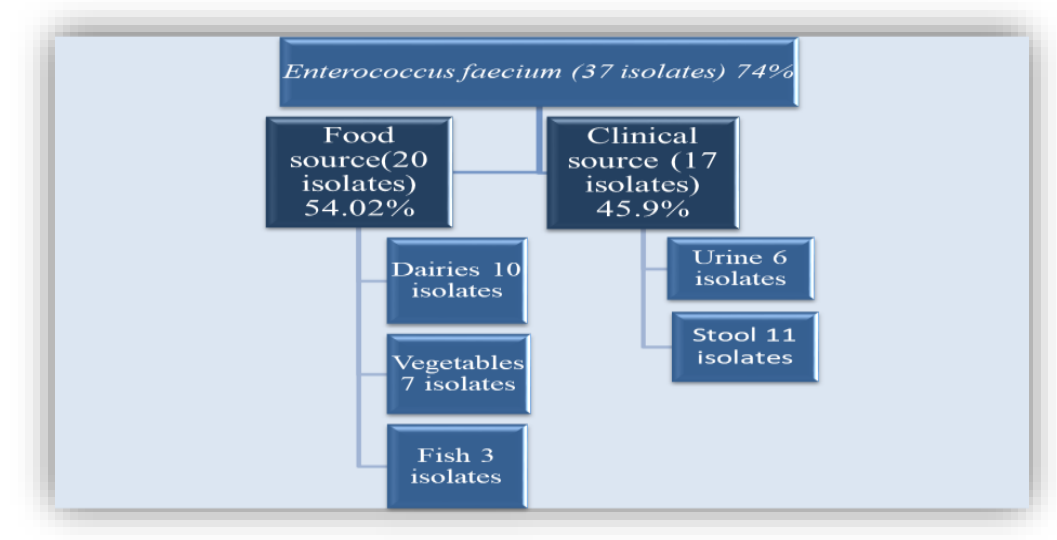

Figure (2): The isolated Enterococcal species with the isolation percentage of each species and its source of isolation

\section{Genotypic Detection of Bacteriocin Production by Enterococcus faecium}

DNA was extracted from thirty seven Enterococcus faecium isolates using genomic extraction kit and the extracted DNA samples were characterized to ensure their purity and quality using agarose gel electrophoresis, then the isolates were detected for their harboring of Enterocin A gene (entA), using conventional PCR technique, and the results revealed that all the isolates were ent A positive, that they amplified entA gene and the PCR product size (362 bp) was detected using agarose gel electrophoresis as shown in Figure (3). 


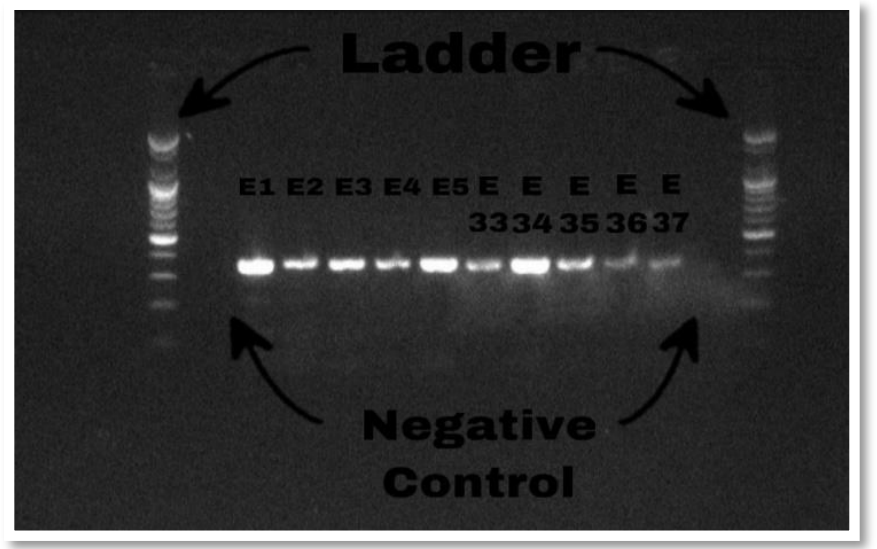

Figure (3): agarose gel electerophoresis of amplified PCR product of $e n t A$ gene (362 bp), (agarose 1.5 \%, 1X TBE buffer, ladder 100bp)

From Figure (3) the positive results of Enterococcus faecium can be noticed, the figure represent ten positive isolates that belongs to E. faecium (both sources, food and clinical, E1-E5 isolated from food sources and E33-E37 isolated from clinical sources). Many researchers reported the presence of ent A gene in Enterococcus spp. especially E. faecium (10). This study also stated that there is no correlation could be found between the presence of enterocin structural genes and the origin of the strain. In this study E. faecium was the most predominant species in bacteriocin production detection, another studies suggested that $E$. faecalis percentage in bacteriocin production is higher than E. faecium (11). Bacteriocins characterize a promising function to regulate bacterial infections, alone or with other antibiotics as a grouping, and also to reduce the probability of food contamination with further microorganisms and may give a promising role to aid in preservation of various types of foods, usually been used as food preservatives, whichever added or formed by starter cultures during fermentation processes (12). (13) Which stated that the Enterococcus contain an antibacterial substances called enterocins that inhibit the growth of closely related foodborne organisms. Antibacterial activity of Enterococcus spp. Isolates against other bacterial isolates from different sources may be due to several factors one of which is the enterocins which consider as the main antibacterial substance produced by Enterococcus spp., antibacterial activity of food-borne Enterococcus spp. Against other pathogenic isolates may give a possible role as sources of bacteriocin preparations to aid in preservation of many types of foods (14). In the current study E. faecium was the most predominant species in bacteriocin production detection (phenotypic and genotypic detection), the variation in inhibitory spectra may be due to several antagonistic factors, among which the production of the known enterocins, such as enterocin $\mathrm{A}$ and $\mathrm{B}$, and there might be an association between enterocins genes such as entB and entA it is possible that both enterocins may act synergistically when expressed in the same culture(15). The use of a specific bacteriocin depends on many characteristics such as effectiveness of pathogen, $\mathrm{PH}$ and heat stability, tolerance and effectiveness in acidic environments, its activity in a combination with some chelating agents and organic acids (16). There are new possibilities how to take advantages of such peptides for the benefit of man and animals. Bacteriocin production has become an important property of probiotic bacteria and the use of bacteriocins to fight certain pathogens may have a brilliant future, for many reasons it is meaningful to separate bacteriocins of gram-positive and gram-negative bacteria, based on chemical structure, molecular weight and thermal stability (17).

\section{Conclusion}

Lactic acid bacteria constantly gain a great interest among an increasing number of researches owing to their huge applications both in food and in pharmaceutical industries. This study indicates the presence of Enterococcus spp. in food and clinical samples and the ability of these bacteria to produce antibacterial 
substances which is active against closely related clinical isolates. Enterocins are one of those antibacterial substances that produced by Enterococcus spp. those substances may play a possible role in the food industry as natural preservatives, these applications of enterocins against pathogenic and food spoilage microorganisms have been established to be effective and consider as safe.

\section{References}

1. Almeida T, Brandão A, Muñoz-Atienza E, Gonçalves A, Torres C, Igrejas G, Hernández PE, Herranz C, Cintas LM, Poeta P. Identification of bacteriocin genes in enterococci isolated from game animals and saltwater fish. Journal of food protection. (2011); 74(8): 1252-1260.

2. Thiercelin ME, Jouhaud L. Reproduction de l'entérocoque; taches centrales; granulations péripheriques et microblastes. C R Seances Soc Biol Fil. (1903); 55: 686-688.

3. Henning C, Gautam D, Muriana P. Identification of Multiple Bacteriocins in Enterococcus spp. Using an Enterococcus-Specific Bacteriocin PCR Array. Microorganisms. (2015); 3(1): 1-16.

4. Hanchi H, Mottawea W, Sebei K, Hammami R. The Genus Enterococcus: Between Probiotic Potential and Safety Concerns-An Update. Frontiers in microbiology. (2018); 9: 1791.

5. Zhong Z, Zhang W, Song Y, Liu W, Xu H, Xi X, Sun Z. Comparative genomic analysis of the genus Enterococcus. Microbiological Research. (2017); 196: 95-105.

6. Klaenhammer TR. Genetics of bacteriocins produced by lactic acid bacteria. FEMS Microbiology Reviews. (1993): 12(1-3); 39-85.

7. Hu X, Mao R, Zhang Y, Teng D, Wang X, Xi D, Wang J. Biotechnical paving of recombinant enterocin A as the candidate of anti-Listeria agent. BMC Microbiology. (2014); 14(1).

8. Swan A. The use of a bile-aesculin medium and of Maxted's technique of Lancefield grouping in the identification of enterococci (group D streptococci). Journal of clinical pathology. (1954); 7(2): 160163.

9. Benson T. Microbiological Applications Laboratory Manual in General Microbiology. (2001). 8th Edition, the McGraw-Hill, New York.

10. De Vuyst L, Foulquié Moreno MR, Revets H. Screening for enterocins and detection of hemolysin and vancomycin resistance in enterococci of different origins. International journal of food microbiology. (2003); 84(3): 299-318.

11. Theppangna W, Murase T, Tokumaru N, Chikumi H, Shimizu E, Otsuki K. Screening of the enterocin genes and antimicrobial activity against pathogenic bacteria in Enterococcus strains obtained from different origins. The Journal of veterinary medical science. (2007); 69(12): 1235-1239.

12. Chikindas ML, Weeks R, Drider D, Chistyakov VA, Dicks LM. Functions and emerging applications of bacteriocins. Current Opinion in Biotechnology. (2018); 49: 23-28.

13. Ogaki MB, Rocha KR, Terra MR, Furlaneto MC, Maia LF. Screening of the Enterocin-Encoding Genes and Antimicrobial Activity in Enterococcus Species. Journal of microbiology and biotechnology. (2016); 26(6): 1026-1034.

14. Szabóová R, Lauková A, Pogány Simonová M, Strompfová V, Chrastinová L. Bacteriocin-Producing Enterococci from Rabbit Meat. Malaysian Journal of Microbiology. (2012); 8(4): 211-218.

15. Silva CC, Silva SP, Ribeiro SC. Application of bacteriocins and protective cultures in dairy food preservation. Frontiers in microbiology. (2018); 9: 594.

16. Sangcharoen N, Klaypradit W, Wilaipun P. Antimicrobial activity optimization of nisin, ascorbic acid and ethylenediamine tetraacetic acid disodium salt (EDTA)against Salmonella enteritidis ATCC13076using response surface methodology. Agriculture and Natural Resources. (2018); 51(5): 355-364.

17. Tiwari SK, Dicks L, Popov IV, Karaseva A, Ermakov AM, Suvorov A, Tagg JR, Weeks R, Chikindas ML. Probiotics at War Against Viruses: What Is Missing From the Picture. Frontiers in microbiology. (2020); 11: 1877. 